Recent Advances in Weed Management 
Bhagirath S. Chauhan · Gulshan Mahajan Editors

\section{Recent Advances in Weed Management}

黛 Springer 


\section{Editors}

Bhagirath S. Chauhan

Queensland Alliance for Agriculture and Food Innovation (QAAFI)

The University of Queensland

Toowoomba

Queensland

Australia
Gulshan Mahajan

Department of Plant Breeding and Genetics

Punjab Agricultural University

Ludhiana

Punjab

India

ISBN 978-1-4939-1018-2

ISBN 978-1-4939-1019-9 (eBook)

DOI 10.1007/978-1-4939-1019-9

Springer New York Heidelberg Dordrecht London

Library of Congress Control Number: 2014940295

(C) Springer Science+Business Media New York 2014

This work is subject to copyright. All rights are reserved by the Publisher, whether the whole or part of the material is concerned, specifically the rights of translation, reprinting, reuse of illustrations, recitation, broadcasting, reproduction on microfilms or in any other physical way, and transmission or information storage and retrieval, electronic adaptation, computer software, or by similar or dissimilar methodology now known or hereafter developed. Exempted from this legal reservation are brief excerpts in connection with reviews or scholarly analysis or material supplied specifically for the purpose of being entered and executed on a computer system, for exclusive use by the purchaser of the work. Duplication of this publication or parts thereof is permitted only under the provisions of the Copyright Law of the Publisher's location, in its current version, and permission for use must always be obtained from Springer. Permissions for use may be obtained through RightsLink at the Copyright Clearance Center. Violations are liable to prosecution under the respective Copyright Law.

The use of general descriptive names, registered names, trademarks, service marks, etc. in this publication does not imply, even in the absence of a specific statement, that such names are exempt from the relevant protective laws and regulations and therefore free for general use.

While the advice and information in this book are believed to be true and accurate at the date of publication, neither the authors nor the editors nor the publisher can accept any legal responsibility for any errors or omissions that may be made. The publisher makes no warranty, express or implied, with respect to the material contained herein.

Printed on acid-free paper

Springer is part of Springer Science+Business Media (www.springer.com) 


\section{Preface}

Agriculture will remain the mainstay to feed the teeming millions in the years to come, which is indeed a tremendous and tough task. The untiring efforts and unflinching zeal of research scientists have transformed agricultural production from mere sustenance into commercial farming. An influx of technologies has transformed the very outlook of the farmers who look toward scientists for support in diverting their farming into profitable enterprises. Efficient weed management approaches are expected to contribute significantly in sustaining and increasing the profitability of agriculture. Advanced research in weed science provides knowledge to the weed science community in formulating research planning as well as developing guidelines for the farmers to save their crops from the menace of weeds.

Weed problems have turned into a continuing struggle for farmers on account of pressure to raise crops and increasing their productivity to meet the ever-growing demands of a fast-growing human population. As per the requirements of various crops, starting from hand weeding, weed control has gone through a number of changes with the advent of new technologies. Herbicide use is increasing globally as agriculture labor is becoming not only scarce, but also costly and not available at the right times. The growth of chemical weed control is attracting scientists and industries to work on herbicides that are eco-friendly and required in low doses. The new molecules that can be used in small quantities help in reducing the herbicide load in the environment, but may create some residue problems and pose high selection pressure. Research, therefore, is now focused on new methods of weed control, such as the use of cultural, biological, and biotechnological approaches that could be integrated with chemical weed control to reduce the herbicide load in the environment.

In this book, an attempt has been made to highlight the emerging weed management issues and to suggest measures to tackle these issues through advanced methods of weed control and better understanding of the ecology and biology of weeds. The authors of each chapter of this book were invited to contribute based on their experience and respective areas of expertise. To our knowledge, no book exists that summarizes the advanced methods of weed control to handle the emerging issues of weed science, and that too in the current changing scenario.

In this book, the thrust areas requiring immediate attention of weed scientists are covered: biology and ecology of weeds, new challenges in weed science and 
research priorities, development of resistance to herbicides in weeds, control of aquatic and parasitic weeds, weed management in conservation agriculture, role of allelopathy in weed management, and integrated approaches for weed management in important crops. Through this book, the message has been given that to make an integrated weed management program a success, it would require improved information and technical assistance to growers in choosing correct methods for controlling the complexes of weeds. The main goal of this book is to provide comprehensive knowledge that will enable the weed scientists and policy makers - in careful planning, designing, and orientation of research and development of weed management - to ensure sustainability in agriculture. We expect that this book will provide sound guidelines for future weed management strategies to boost agricultural production by allowing the readers to benefit from the collective experience of others instead of learning through "the hard way."

Bhagirath S. Chauhan

Gulshan Mahajan 


\section{Contents}

1 Ecologically Based Weed Management Strategies

Bhagirath S. Chauhan and Gurjeet S. Gill

2 Ecology and Management of Weeds in a Changing Climate

David R. Clements, Antonio DiTommaso and Terho Hyvönen

3 Role of Allelopathy in Weed Management

Ahmad Nawaz, Muhammad Farooq, Sardar Alam Cheema and Zahid Ata Cheema

4 Weed Management in Organic Farming

Eric Gallandt

5 Weed Management in Conservation Agriculture Systems

Seyed Vahid Eslami

6 Integrated Weed Management in Rice.

Gulshan Mahajan, Bhagirath S. Chauhan and Vivek Kumar

7 Recent Advances in Weed Management in Wheat.

Samunder Singh

8 Integrated Weed Management in Maize

Amit J. Jhala, Stevan Z. Knezevic, Zahoor A. Ganie

and Megh Singh

9 Integrated Weed Management in Cotton.

Mehmet Nedim Doğan, Khawar Jabran and Aydin Unay

10 Integrated Weed Management in Soybean

Stevan Z. Knezevic 
11 Integrated Weed Management in Horticultural Crops

Darren E. Robinson

12 Integrated Weed Management in Plantation Crops

255

Rakesh Deosharan Singh, Rakesh Kumar Sud

and Probir Kumar Pal

13 Management of Aquatic Weeds

281

Robert M. Durborow

14 Weed Management for Parasitic Weeds

Radi Aly and Neeraj Kumar Dubey

15 Herbicide Resistance in Weeds and Crops: Challenges and Opportunities

Hugh J. Beckie

16 Challenges and Opportunities in Weed Management Under

a Changing Agricultural Scenario

K. K. Barman, V. P. Singh, R. P. Dubey, P. K. Singh, Anil Dixit and A. R. Sharma

17 Strengthening Farmers' Knowledge for Better Weed Management in Developing Countries.

Narayana Rao Adusumilli, R. K. Malik, Ashok Yadav and J. K. Ladha

Index 


\section{Contributors}

Narayana Rao Adusumilli Resilient Dryland Systems and International Rice Research Institute (IRRI), International Crop Research Institute for the Semi-Arid Tropics (ICRISAT), Hyderabad, India

Radi Aly Department of Plant Pathology and Weed Research, Newe-Yaar Research Center, Haifa, Israel

K. K. Barman Directorate of Weed Science Research, Indian Council of Agricultural Research, Jabalpur, Madhya Pradesh, India

Hugh J. Beckie Saskatoon Research Centre, Agriculture and Agri-Food Canada, Saskatoon, SK, Canada

Bhagirath S. Chauhan Queensland Alliance for Agriculture and Food Innovation (QAAFI), The University of Queensland, Queensland, Australia

Sardar Alam Cheema Allelopathy and Eco-physiology Lab, Department of Agronomy, University of Agriculture, Faisalabad, Pakistan

Zahid Ata Cheema Allelopathy and Eco-physiology Lab, Department of Agronomy, University of Agriculture, Faisalabad, Pakistan

David R. Clements Department of Biology, Trinity Western University, Langley, BC, Canada

Antonio DiTommaso Department of Crop and Soil Sciences, Cornell University, Ithaca, NY, USA

Anil Dixit Directorate of Weed Science Research, Indian Council of Agricultural Research, Jabalpur, Madhya Pradesh, India

Mehmet Nedim Doğan Department of Plant Protection, Adnan Menderes University, Aydin, Turkey

Neeraj Kumar Dubey Unit of Weed Science, Newe-Yaar Research Center, Haifa, Israel 
R. P. Dubey Directorate of Weed Science Research, Indian Council of Agricultural Research, Jabalpur, Madhya Pradesh, India

Robert M. Durborow Division of Aquaculture, College of Agriculture, Food Science and Sustainable Systems, Kentucky State University, Aquaculture Research Center, Frankfort, KY, USA

Seyed Vahid Eslami Agronomy Department, Faculty of Agriculture, University of Birjand, Birjand, South Khorasan, Iran

Muhammad Farooq Allelopathy and Eco-physiology Lab, Department of Agronomy, University of Agriculture, Faisalabad, Pakistan

Eric Gallandt School of Food and Agriculture, University of Maine, Orono, ME, USA

Zahoor A. Ganie Department of Agronomy and Horticulture, University of Nebraska-Lincoln, Lincoln, NE, USA

Gurjeet S. Gill Department of Agriculture and Animal Science, University of Adelaide, Adelaide, SA, Australia

Terho Hyvönen MTT Agrifood Research Finland, Plant Production Research, Planta, Jokioinen, Finland

Khawar Jabran Department of Plant Protection, Adnan Menderes University, Aydin, Turkey

Amit J. Jhala Department of Agronomy and Horticulture, University of NebraskaLincoln, Lincoln, NE, USA

Stevan Z. Knezevic Northeast Research and Extension Center, Department of Agronomy and Horticulture, Haskell Agricultural Laboratory, University of Nebraska-Lincoln, Concord, NE, USA

Vivek Kumar Department of Plant Breeding and Genetics, College of Agriculture, Punjab Agricultural University, Ludhiana, Punjab, India

J. K. Ladha International Rice Research Institute (IRRI)/India Office, New Delhi, India

Gulshan Mahajan Department of Plant Breeding and Genetics, Punjab Agricultural University, Ludhiana, Punjab, India

R. K. Malik Cereal Systems Initiative for South Asia (CSISA) Hub for Eastern U.P. and Bihar, Patna, India

Ahmad Nawaz Allelopathy and Eco-physiology Lab, Department of Agronomy, University of Agriculture, Faisalabad, Pakistan

Probir Kumar Pal Natural Plant Products Division, Council of Scientific and Industrial Research (CSIR)-Institute of Himalayan Bioresource Technology, Palampur, Himachal Pradesh, India 
Darren E. Robinson Department of Plant Agriculture, University of Guelph, Ridgetown, ON, Canada

A. R. Sharma Directorate of Weed Science Research, Indian Council of Agricultural Research, Jabalpur, Madhya Pradesh, India

Megh Singh Citrus Research and Education Center, University of Florida, Lake Alfred, FL, USA

P. K. Singh Directorate of Weed Science Research, Indian Council of Agricultural Research, Jabalpur, Madhya Pradesh, India

Rakesh Deosharan Singh Department of Biodiversity, Council of Scientific and Industrial Research (CSIR)-Institute of Himalayan Bioresource Technology, Palampur, Himachal Pradesh, India

Samunder Singh Department of Agronomy, CCS Haryana Agricultural University, Hisar, India

V. P. Singh Directorate of Weed Science Research, Indian Council of Agricultural Research, Jabalpur, Madhya Pradesh, India

Rakesh Kumar Sud Hill Area Tea Science Division, Council of Scientific and Industrial Research (CSIR)-Institute of Himalayan Bioresource Technology, Palampur, Himachal Pradesh, India

Aydin Unay Department of Field Crops, Agricultural Faculty, Adnan Menderes University, Aydin, Turkey

Ashok Yadav Weed Science, Department of Agronomy, Chaudhary Charan Singh Haryana Agricultural University, Hisar, India 